This item was submitted to Loughborough's Research Repository by the author.

Items in Figshare are protected by copyright, with all rights reserved, unless otherwise indicated.

\title{
Embroidered wearable antennas using conductive threads with different stitch spacings
}

PLEASE CITE THE PUBLISHED VERSION

http://ieeexplore.ieee.org/

PUBLISHER

Loughborough University (@ IEEE)

VERSION

AM (Accepted Manuscript)

LICENCE

CC BY-NC-ND 4.0

\section{REPOSITORY RECORD}

Zhang, Shiyu, Alford Chauraya, W.G. Whittow, R.D. Seager, and J.C. Vardaxoglou. 2019. "Embroidered Wearable Antennas Using Conductive Threads with Different Stitch Spacings". figshare.

https://hdl.handle.net/2134/11521. 
This item was submitted to Loughborough's Institutional Repository (https://dspace.lboro.ac.uk/) by the author and is made available under the following Creative Commons Licence conditions.

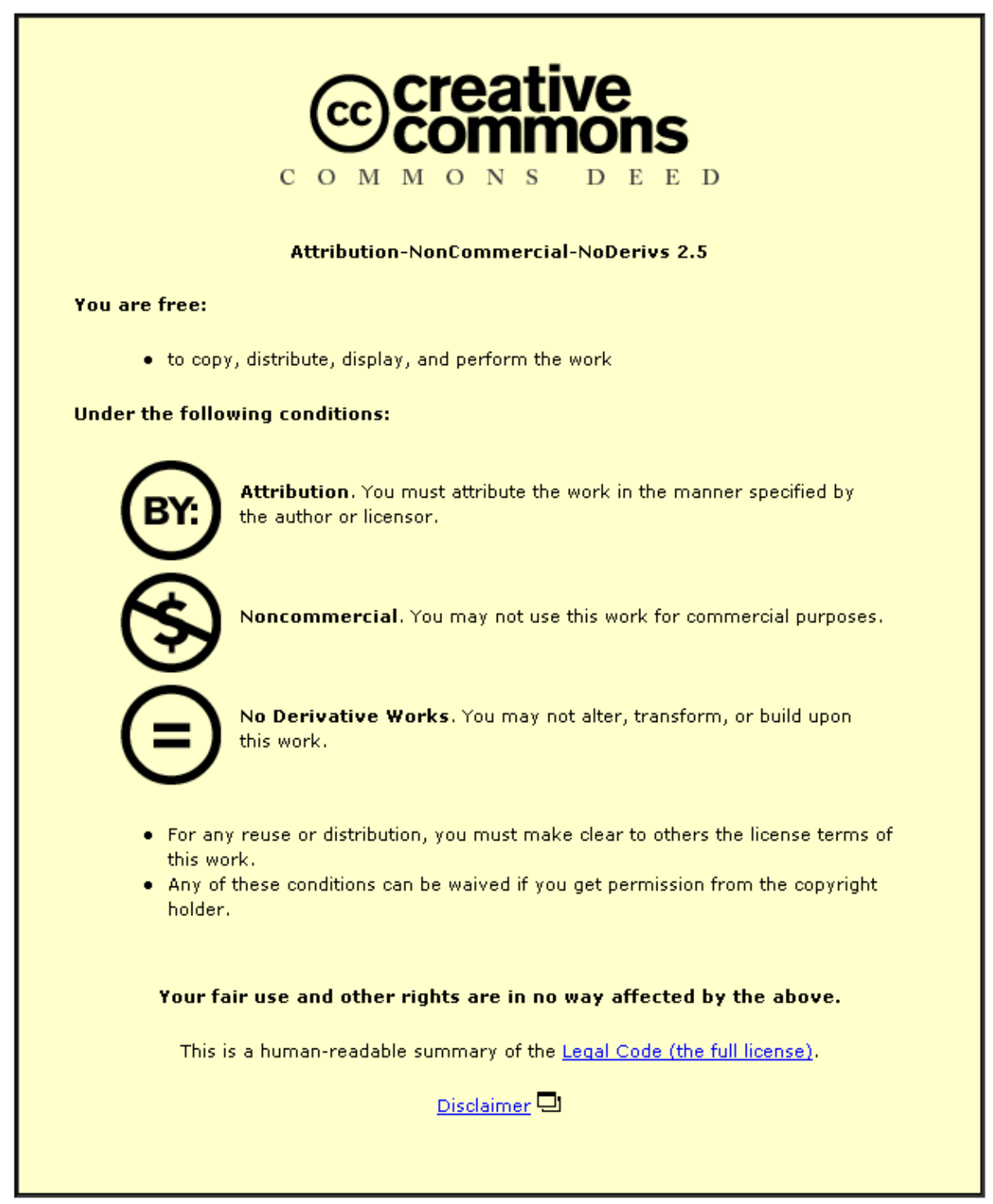

For the full text of this licence, please go to: http://creativecommons.org/licenses/by-nc-nd/2.5/ 


\title{
Embroidered Wearable Antennas Using Conductive Threads with Different Stitch Spacings
}

\author{
Shiyu Zhang \#, Alford Chauraya ${ }^{\#}$, William Whittow ${ }^{\wedge}$, Rob Seager ${ }^{\#}$, Tessa Acti ${ }^{*}$, Tilak Dias ${ }^{*}$, Yiannis Vardaxoglou \\ \#School of Electronic, Electrical and \\ Systems Engineering, \\ Loughborough University \\ s.zhang@lboro.ac.uk, \\ r.d.seager@lboro.ac.uk \\ $\wedge$ Antrum Ltd, Rutland Hall, \\ Enterprise Office, \\ Loughborough University \\ Campus \\ will.whittow@antrum.co.uk \\ *Centre for Research in Advanced \\ Textiles (CReATe), \\ School or Art and Design, \\ Nottingham Trent University \\ tilak.dias@ntu.ac.uk
}

\begin{abstract}
This paper is focused on using conductive threads to design flexible antennas with textile features which means antennas can be embroidered directly into normal clothes. The fabric microstrip antennas are made from commercial conductive threads. The gain and efficiency of fabric antennas have been measured and compared with a reference copper patch antenna. Effects from different stitches geometries within the fabric antenna are discussed. The results demonstrate the feasibility of wearable antennas.
\end{abstract}

Keywords-conductive thread; fabric antenna; antenna gain measurement; wearable; embroidery

\section{INTRODUCTION}

Development in wearable electronics and antennas is driven by the demand for lighter and smaller personal electronic devices. Integrating antenna into normal garments would allow lower-profile and more portable electronics to be practical but without affecting their performance. There are a number of applications for wearable antenna include military, aerospace, rescue, medicine, fashion, etc. [1-4]. Advantages include hands-free operation and comfort to consumers. A wearable antenna is normally made by flexible conductive materials [5][6], which guarantee the textile characteristics of clothing (soft and flexible). The challenge of wearable antennas is the compromise between these textile characteristics and the antenna electromagnetic performance.

Microstrip antennas are an easy way to realize wearable antennas as they have a low-profile and can be contoured around the body. Researchers had found several alternative materials to reduce the substrate loss and improve textile microstrip antenna performance, such as EBG materials [7] and polymer composites [8]. Meanwhile the geometries of wearable antennas are flexible and enable bending and folding. The RF performance of wearable antennas are most significantly affected by bending in the E-plane [9][10].

This work focuses on investigating embroidered fabric antennas that are stitched with conductive threads. These embroidered antennas do not require extra adhesive glue or sewing to attach them, which is conducive to being washed and extend consumer lifecycle. Computerised embroidery has been adopted to fabricate the textile antennas in this project. This technology provides high speed, mass-manufacturing capability, accurate and easily modified embroidered antenna designs. The antenna can be automatically integrated into the manufacturing process which further reduces the costs and adds to the aesthetic appeal. The computerised embroidery machinery was developed by Nottingham Trent University, details of operation were discussed in [11].

The RF characteristics of the conductive textiles have been discussed by several authors [12-14]. Our research on textile transmission lines investigated that RF performance of conductive fabric made components were impacted by a number of parameters including the stitch direction, stitch material, spacing between the two stitches [11]. Better conduction and lower loss can be achieved by stitching threads in a direction parallel to the current flow. Furthermore, simulations indicated that using a continuous thread or connecting along the ends of threads on boundary of the antenna, could enhance the efficiency [15].

Our previous fabric antenna research illustrated the performance of fabricated antennas was not only highly dependent on the stitched parameters mentioned before, but also the loss of substrate and the impedance match of the feed [16]. In order to make the experiments more controllable, the microstrip antennas were fed with a coax probe feed in this paper. This was advantageous compared to an inset feed as it allowed the antenna to obtain its best match point by connecting the coax at different position within the fabric patch.

\section{CONDUCTIVE FABRIC ANTENNA DESIGN}

The fabric patch antenna was made into a $46 \mathrm{~mm}$ x $35 \mathrm{~mm}$ rectangle using AmberStrand $\AA$ Silver Clad Fiber. The stitch direction discussed in this paper was parallel to the longer side of the patch. The feed point was $6.5 \mathrm{~mm}$ away from the central point of the patch. The geometry is shown in Figure 1.

This work was funded by the IeMRC 


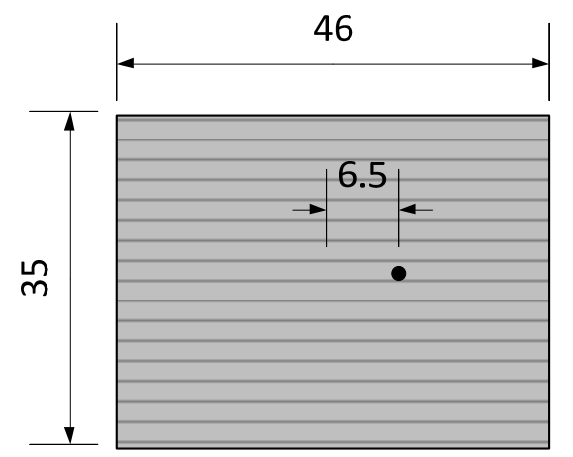

Figure 1. Geometry of fabric patch antenna (unit: $\mathrm{mm}$ )

The stitch spacing indicates the distance between two parallel stitches. Two fabric patches with different stitch spacing $0.4 \mathrm{~mm}$ and $0.8 \mathrm{~mm}$ were made. An enlarged detail of the patch stitches was observed using a microscope, shown in Figure 2. The fabric patches were placed on a $130 \mathrm{~mm} \times 128$ $\mathrm{mm}, 1.9 \mathrm{~mm}$ thick Rogers ${ }^{\circledR} 6006$ substrate. The dielectric constant of the substrate is 6.15 and the loss tangent is 0.0027 . The same sized copper patch antenna on Rogers 6006 was made for reference. All the antennas were fed by $50 \Omega$ coax wires.

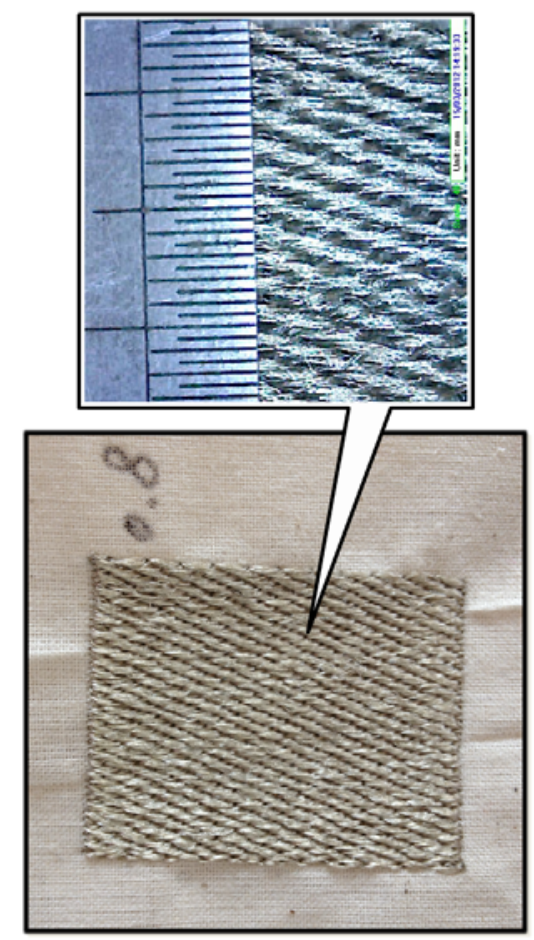

Figure 2. $0.8 \mathrm{~mm}$ stitch spacing fabric detail under microscope

The antennas were measured in the anechoic chamber at Loughborough University. Paper tape was used to attach the

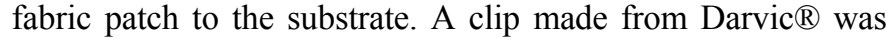
pressed onto the patch in order to flatten the fabric surface and provide a good connection between the probe and patch. The antenna in the chamber is shown in Figure 3. As a comparison the copper patch was attached in the same way.

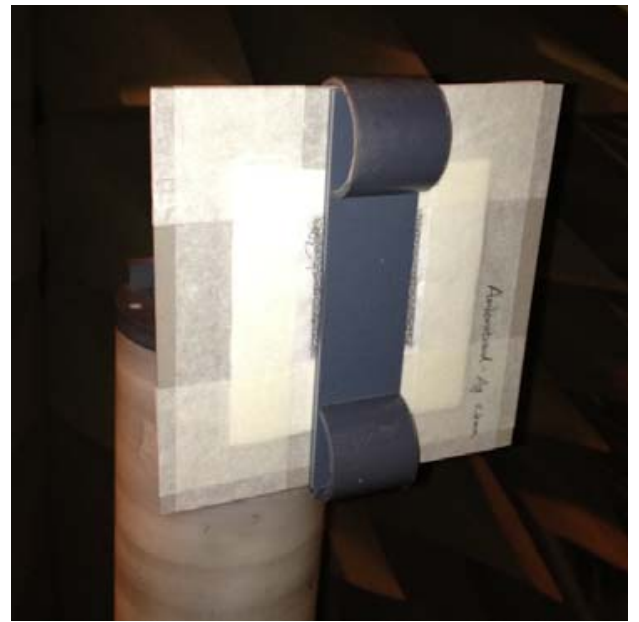

Figure 3. Fabric antenna in the anechoic chamber

Measured S11 results are shown in Figure 4. It is shown that all the three patches were well matched at their resonant frequencies: return loss of copper patch is $-22.8 \mathrm{~dB}$ at 1.39 $\mathrm{GHz}$, with $9.5 \mathrm{MHz} 10 \mathrm{~dB}$ bandwidth. The fabric patches resonances are slightly lower than copper, this is because the fabric patch sizes are slightly different from copper patch and they are thicker than the copper, S11 of Amberstrand Silver 0.4 $\mathrm{mm}$ (stitch spacing) patch is $-34.6 \mathrm{~dB}$ at $1.4 \mathrm{GHz}$ with 19.9 $\mathrm{MHz} 10 \mathrm{~dB}$ bandwidth, whist Amberstrand Silver $0.8 \mathrm{~mm}$ is $23.7 \mathrm{~dB}$ at $1.3 \mathrm{GHz}$ with highest $10 \mathrm{~dB}$ bandwidth $21.6 \mathrm{MHz}$.

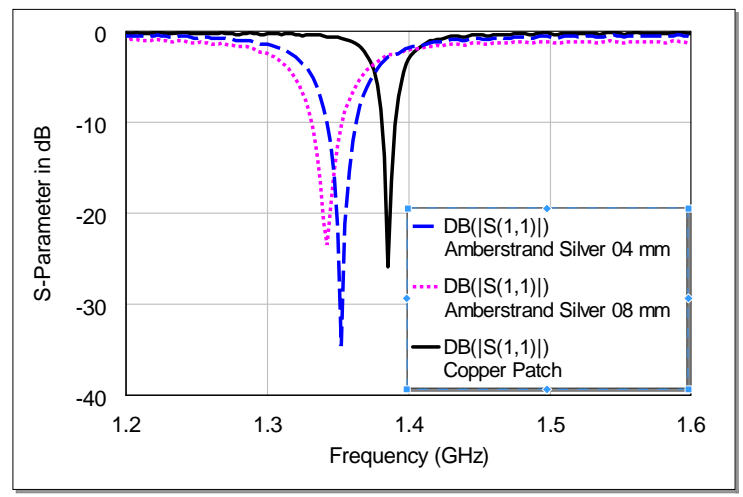

Figure 4. Measured S11 results of fabric patch and copper patch antennas

The gain and efficiency results are shown in Table 1 . The measured results indicated that the antenna gain was dependent on the stitch spacing. The antenna with $0.4 \mathrm{~mm}$ stitch spacing has a $2.31 \mathrm{dBi}$ gain, $6.56 \mathrm{dBi}$ directivity and $37.6 \%$ efficiency and it is better than the antenna with $0.8 \mathrm{~mm}$ stitch spacing: 1.1 $\mathrm{dBi}$ gain, $6.4 \mathrm{dBi}$ directivity and $29.6 \%$ efficiency. Therefore the results indicate that reducing the stitch spacing improves the antenna performance. Compared with the same sized copper patch, both fabric antennas had a lower gain and efficiency. The lower gain and efficiency is due to the complexity of the discontinuous nature of embroidery and the losses when the current moves from one thread to its nearest neighbour, which results in the lower effective conductivity. 
TABLE I. MEASURED PATCH RESUlTS

\begin{tabular}{|c|c|c|c|c|}
\hline \multirow{2}{*}{$\begin{array}{c}\text { Measured } \\
\text { data }\end{array}$} & \multicolumn{4}{|c|}{ Antenna name } \\
\hline & Simulation & $\begin{array}{l}\text { Copper } \\
\text { patch }\end{array}$ & $\begin{array}{c}\text { Stitch } \\
\text { spacing } \\
=0.4 \mathrm{~mm}\end{array}$ & $\begin{array}{c}\text { Stitch } \\
\text { spacing } \\
=0.8 \mathrm{~mm}\end{array}$ \\
\hline $\mathrm{S} 11$ in $\mathrm{dB}$ & -19.8 & -22.8 & -34.6 & -23.7 \\
\hline $\begin{array}{c}\text { Frequency } \\
\quad(\mathrm{GHz})\end{array}$ & 1.3 & 1.4 & 1.4 & 1.3 \\
\hline $\begin{array}{c}10 \mathrm{~dB} \\
\text { Bandwidth } \\
(\mathrm{MHz})\end{array}$ & 8.5 & 9.5 & 19.9 & 21.6 \\
\hline $\begin{array}{c}\text { Gain in } \\
\mathrm{dBi}\end{array}$ & 6.4 & 6.5 & 2.3 & 1.1 \\
\hline $\begin{array}{l}\text { Directivity } \\
\text { in } \mathrm{dBi}\end{array}$ & 6.7 & 7.0 & 6.6 & 6.4 \\
\hline $\begin{array}{l}\text { Antenna } \\
\text { Efficiency }\end{array}$ & $92.5 \%$ & $89.9 \%$ & $37.6 \%$ & $29.6 \%$ \\
\hline
\end{tabular}

Radiation patterns of the simulation and three measured antennas are shown in Figure 5-8. The pattern shapes were affected by the positioner in the anechoic chamber, and this was counted in the simulation. Compared with the simulation and copper patch, the two embroidered antennas produced similar directivity patterns.

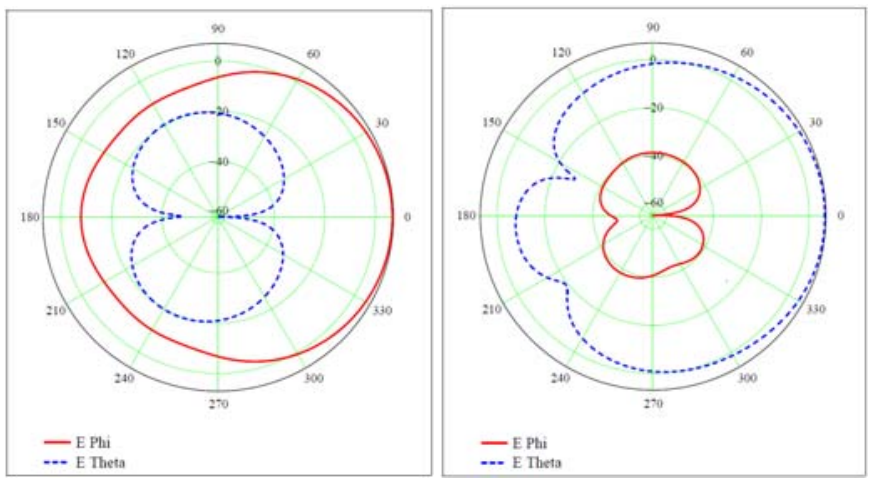

Figure 5. E-field plot of simulated patch antenna, Elevation Plane Phi $=0^{\circ}$ (above), $\mathrm{Phi}=90^{\circ}$ (bottom)
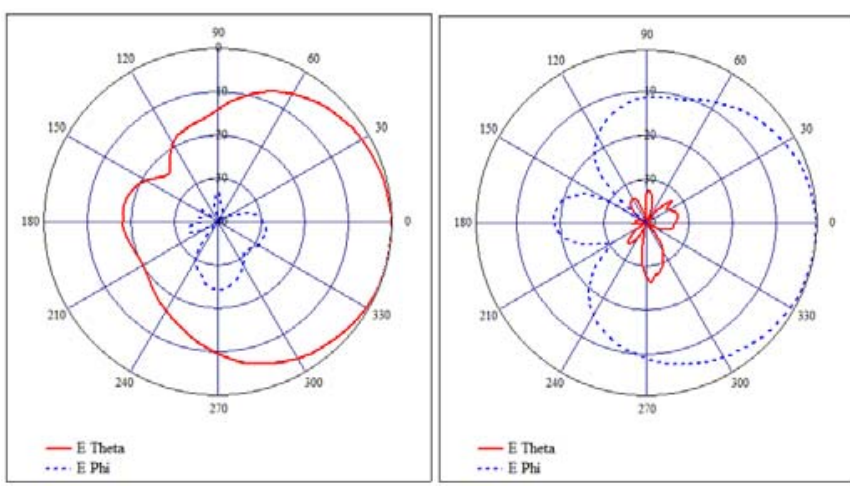

- E Theti

Figure 6. E-field plot of copper patch antenna, Elevation Plane $\mathrm{Phi}=0$ (above), Phi $=90^{\circ}$ (bottom)
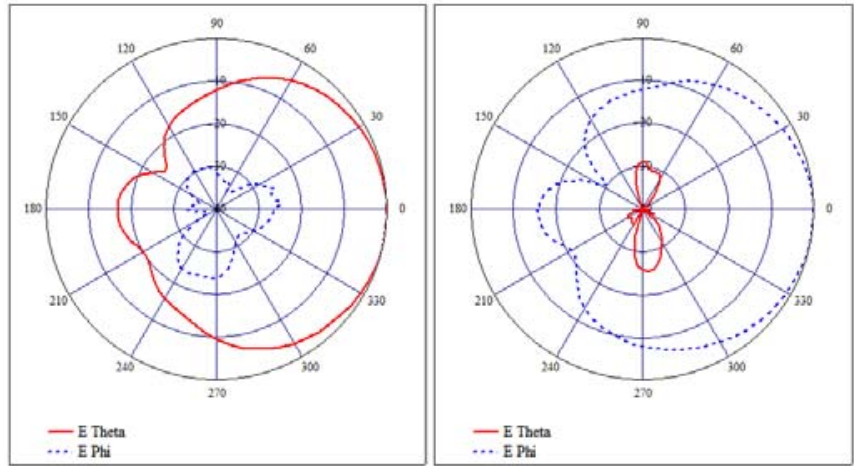

Figure 7. E-field plot of Amberstrand antenan with $0.4 \mathrm{~mm}$ stitch spacing, Elevation Plane $\mathrm{Phi}=0^{\circ}$ (above), $\mathrm{Phi}=90^{\circ}$ (bottom)

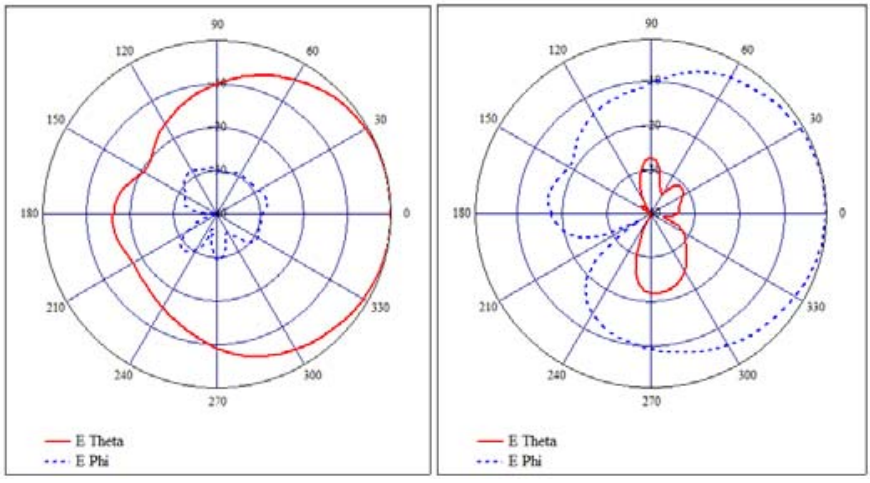

Figure 8. E-field plot of Amberstrand antenna with $0.8 \mathrm{~mm}$ stitch spacing, Elevation Plane $\mathrm{Phi}=0^{\circ}$ (above), $\mathrm{Phi}=90^{\circ}$ (bottom) 


\section{CONCLUSIONS}

This paper has presented embroidered fabric microstrip antennas using conductive thread. Two fabric patch antenna were made and the antenna gain and efficiency were compared with a same sized reference copper patch antenna. The effects from the stitch spacing to the gain and directivity were discussed. The loss is introduced by the connection between stitches. Closer stitch spacing can improve the electrical connection between neighbouring stitches and improve better antenna performance.

\section{ACKNOWLEDGEMENT}

The authors are grateful to Rogers Corporation for supplying substrate materials.

\section{REFERENCES}

[1] P. Massey, "GSM fabric antenna for mobile phones integrated within clothing," Antennas and Propagation Society International Symposium, 2001. IEEE, vol. 3, pp. 452-455, 2001.

[2] T. Kennedy, P. Fink, and A. Chu, "Body-worn e-textile antennas The good, the low-mass, and the conformal," IEEE Transactions on Antennas and Propagation, vol. 57, no. 4, pp. 910-918, 2009.

[3] T. Kellomaki, W. G. Whittow, J. Heikkinen, and L. Kettunen, "2.4 GHz plaster antennas for health monitoring," in Antennas and Propagation, 2009. EuCAP 2009. 3rd European Conference on, 2009, pp. 211-215.

[4] C. Hertleer, H. Rogier, L. Vallozzi, and L. Van Langenhove, “A Textile Antenna for Off-Body Communication Integrated Into Protective Clothing for Firefighters," IEEE Transactions on Antennas and Propagation, vol. 57, no. 4, pp. 919-925, Apr. 2009.

[5] J. Lilja and P. Salonen, "Textile material characterization for SoftWear antennas," in MILCOM 2009 - 2009 IEEE Military Communications Conference, 2009, pp. 1-7.

[6] I. Locher, M. Klemm, and T. Kirstein, "Design and characterization of purely textile patch antennas," IEEE Transactions on Advanced Packaging, vol. 29, no. 4, pp. 777-788, 2006.
S. Zhu and R. Langley, "Dual-band wearable textile antenna on an EBG substrate," Antennas and Propagation, IEEE Transactions on, vol. 57, no. 4, pp. 926-935, 2009.

[8] Y. Bayram et al., "E-textile conductors and polymer composites for conformal lightweight antennas," Antennas and Propagation, IEEE Transactions on, vol. 58, no. 8, pp. 2732-2736, 2010.

[9] P. Salonen and Y. Rahmat-Samii, "Textile antennas: Effects of antenna bending on input matching and impedance bandwidth," Aerospace and Electronic Systems Magazine, IEEE, vol. 22, pp. 10$14,2007$.

[10] Q. Bai and R. Langley, "Wearable EBG antenna bending and crumpling," in 2009 Loughborough Antennas \& Propagation Conference, 2009, no. November, pp. 201-204.

[11] Acti, T.; Shiyu Zhang; Chauraya, A.; Whittow, W.; Seager, R.; Dias T.; Vardaxoglou, Y.; , "High performance flexible fabric electronics for megahertz frequency communications,"Antennas and Propagation Conference (LAPC), 2011 Loughborough , vol., no., pp.1-4, 14-15 Nov. 2011.

[12] Y. Ouyang and W. Chappell, "Measurement of electrotextiles for high frequency applications," Microwave Symposium Digest, 2005 IEEE MTT-S International, p. 4, 2005.

[13] R. Shaw, B. Long, D. Werner, and A. Gavrin, "The characterization of conductive textile materials intended for radio frequency applications," Antennas and Antennas and Propagation Magazine, IEEE, vol. 49, no. 3, pp. 28-40, 2007.

[14] J. L. Volakis, L. Zhang, Z. Wang, and Y. Bayram, "Embroidered flexible RF electronics," 2012 IEEE International Workshop on Antenna Technology (iWAT), no. 1, pp. 8-11, Mar. 2012.

[15] Shiyu Zhang; Chauraya, A.; Whittow, W.; Seager, R.; Acti, T.; Dias, T.; Vardaxoglou, Y.C.; , "Simulation Methodology to Model the Behavior of Wearable Antennas Composed of Embroidered Conductive Thread," 2012 IEEE International Symposium on Antennas and Propagation and USNC-URSI National Radio Science Meeting, Chicago, July 2012,

[16] Chauraya, A.; Shiyu Zhang; Whittow, W.; Acti, T.; Seager, R.; Dias, T.; Vardaxoglou, Y.C.; , "Addressing the challenges of fabricating microwave antennas using conductive threads," Antennas and Propagation (EUCAP), 2012 6th European Conference on, vol., no., pp.1365-1367, 26-30 March 2012 